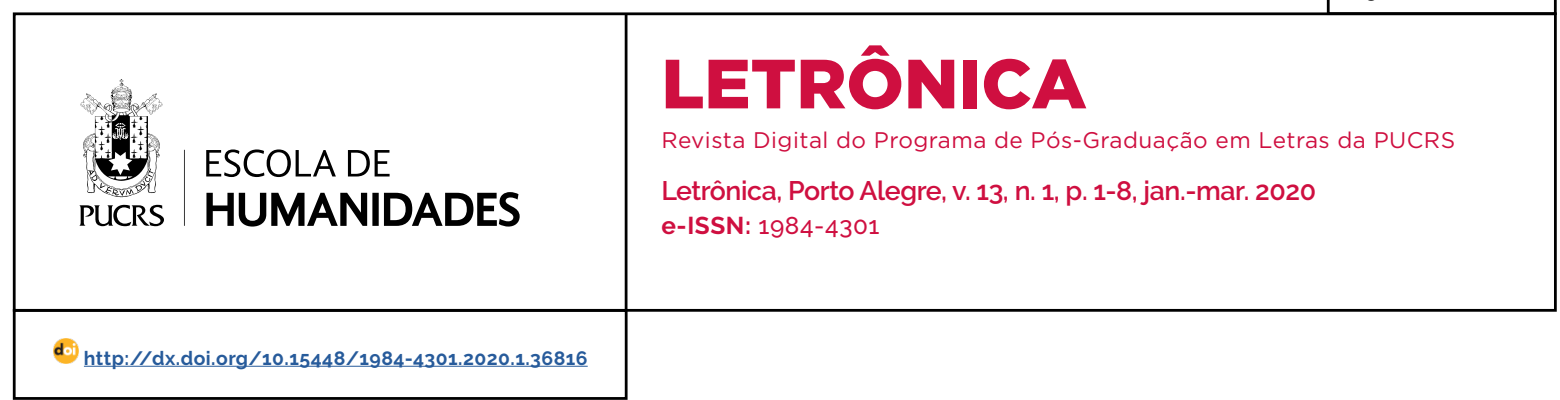

EDITORIAL

\title{
A escrita de mulheres, as mulheres na escrita: histórias de vida na literatura da América Latina
}

Women's writing, women in writing: life stories in Latin America literature

\author{
Regina Kohlrausch ${ }^{1}$ \\ orcid.org/0000-0002-1410-7429 \\ regina.kohlrausch@pucrs.br
}

\section{Sara Beatriz Guardia ${ }^{2}$}

orcid.org/0000-0003-0364-33.97 sarabeatriz.quardia@gmail.com

\section{Luís Alberto dos Santos Paz Filho ${ }^{1}$ \\ orcid.org/0000-0003-4667-8186 luis.alberto@acad.pucrs.br}

Recebido em: 9 jan. 2020. Aprovado em: 9 jan. 2020. Publicado em: 7 abr. 2020

\section{(c) (i)}

Artigo está licenciado sob forma de uma licença Creative Commons Atribuição 4.0 Internacional.
Recorrendo à história sobre o percurso da autoria feminina na literatura, observa-se que os movimentos feministas na década de 60 do século XX foram constituidos por grupos mais ou tão ativos que outras relevantes manifestações dos séculos anteriores. Em outras palavras, ampliouse a discussão e a pesquisa acadêmica sobre o universo feminino. Desde os fins do século XIX e, principalmente, no século XX, conforme explica Luiza Lobo (1998)3, "a principal transformação por que passou a literatura de autoria feminina é a conscientização da escritora quanto a sua liberdade e autonomia e a possibilidade de trabalhar e criar a sua independência financeira", ocorrendo assim "uma paulatina mudança da condição "feminina" para a condição "feminista". Seguindo essa perspectiva, segundo Zolin (2012), a mulher penetra na sociedade letrada em consequência do feminismo que oportunizou sua atuação como literatas e também como críticas: "De um lado, a crítica literária, antes de domínio quase exclusivamente masculino, passou a ser praticada por mulheres; de outro, estas passaram a escrever mais como literatas, livres dos temores da rejeição e do escândalo" (ZOLIN, 2012, p.328).

Nessa direção, Márcia Hoppe Navarro (1995), ao comentar sobre a ausência de mulheres no denominado "boom da literatura latinoamericana", na década de 60 do século passado, afirma que somente duas décadas depois que a escrita das mulheres começou a receber a merecida atenção e que esse aumento da produção literária de mulheres pode ser "relacionado com o panorama geral de mudanças provenientes dos movimentos feministas iniciados nas duas décadas precedentes". (NAVARRO, 1995, p. 13). Para Navarro, "essas obras, publicadas durante os 80, se caracterizam pelo resgate da força da mulher, que emerge com a habilidade de fazer sua própria história". A estudiosa destaca que é importante observar como se processa essa habilidade de fazer a própria história nos romances através do papel coincidente das personagens femininas. Segundo ela, e isso se comprova também nas análises aqui

\footnotetext{
Pontifícia Universidade Católica do Rio Grande do Sul (PUCRS), Porto Alegre, RS, Brasil.

Universidad de San Martín de Porres(USMP), Lima, Peru.

LOBO, Luísa. Literatura de autoria feminina na América Latina. Rev. Mulher e Literatura, Rio de Janeiro, 1998. Disponivel em: http://wwww. openlink.com.br/nielm/revista.htm. Acesso em: 30 dez. 2019.
} 
publicadas, nessas narrativas, na maioria das vezes, a mulher é a protagonista e narradora da história, adquirindo um papel preponderante, uma função na narrativa, dentre elas, como escritora. Navarro salienta que não importa que espécie de escritura produz essas escritoras ficcionais:

Pode ser escritora a partir da experiência pessoal que se abre ao social e do jornalismo como a Cristina de Más allá de las máscaras, de Lucia Guerra, e de Irene em De amory de sombras, de Isabel Allende; romancista como Alba ou escritora de diário como Clara, ambas em La casa de losespiritus; historiadora/biógrafa como Breta em A república dos sonhos, de Nélida Piñon; ou até mesmo autora de telenovelas como Eva Luna. O que realmente importa é a forma como essas mulheres adquirem voz para escrever suas histórias; uma voz, várias vozes, que subvertem os todo-poderosos relatos ficcionais de orientação masculina (NAVARRO, 1995, p. 15).

Em relação à profissão escritora, na vida real, Virginia Woolf, romancista consagrada, que se dedicou também à escrita de ensaios, refletiu acerca da inserção feminina no universo profissional e intelectual de sua época. Entre tais ensaios, destaco "Profissões para mulheres" escrito para atender ao convite da Sociedade

Nacional de Auxílio às Mulheres, cuja leitura deu-se em 21 de janeiro de 19314.Para falar de suas experiências profissionais, Woolf começa afirmando: "Sou mulher, é verdade; tenho emprego, é verdade; mas que experiências tive eu? Minha profissão é a literatura; e é a profissão que, tirando o palco, menos experiência oferece às mulheres - menos, quero dizer, que sejam específicas das mulheres" (WOOLF, 2017, p. 9). Reconhecendo o legado anterior, relata como virou jornalista e como gastou o primeiro salário: escreveu, colocou os escritos em um envelope, enviou-o via correio, um mês depois recebeu um cheque e, com o valor, "no lugar de gastar com pão e manteiga, aluguel, meias, sapatos ou com a conta do açougueiro", comprou um gato persa (WOOLF, 2017, p. 9).

Considerando que não merece ser chamada de profissional porque não conhece as lutas e as dificuldades da vida de uma mulher profissional, ela pergunta "existe coisa mais fácil do que escrever artigos e comprar gatos?", e responde: "Mas esperem aí. Os artigos têm de ser sobre alguma coisa" (2017, p. 11). Partindo dessa questão, Woolf relata duas experiências genuínas da sua vida como profissional da literatura. A primeira, "matar o Anjo do Lar" porque se não a matasse. seria morta por ela, pois, para o Anjo do Lar, as mulheres não podem tratar com liberdade e franqueza temas sobre relações humanas, morais e sexuais. Para o "Anjo do Lar", escreve Woolf, as mulheres "precisam agradar, precisam conciliar, precisam - falando sem rodeios - mentir". Para Woolf, matar o "Anjo do Lar" fazia parte da atividade de uma escritora (WOOLF, 2017, p. 1314). A segunda, "falar a verdade sobre minhas experiências do corpo, creio que não resolvi. Duvido que alguma mulher já tenha resolvido. Os obstáculos ainda são imensamente grandes - e muito dificeis de definir" (WOOLF, 2017, p. 17).

Woolf explica que olhando de fora parece simples escrever livros, mas, por dentro, "a questão é muito diferente" já que a escritora "ainda tem muitos fantasmas a combater, muitos preconceitos a vencer" (WOOLF, 2017, p. 17). $\mathrm{Na}$ verdade, projeta a ensaísta em janeiro de 1931, "ainda vai levar muito tempo até que uma mulher possa se sentar e escrever um livro sem se encontrar com um fantasma que precise matar, uma rocha que precise enfrentar". E pergunta "se é assim na literatura, a profissão mais livre de todas para as mulheres", o que sobra às "novas profissões que agora vocês estão exercendo pela primeira vez?" (WOOLF, 2017, p. 17).

Os anos passaram e os questionamentos sobre o ingresso da mulher ou da autoria feminina na literatura continuam presentes nos estudos acadêmicos com o objetivo de recuperar o espaço negado e a invisibilidade do passado e garantir, no presente, a visibilidade das vozes em ação. É na escrita, conforme Cixous (1997), que as mulheres encontram um meio de libertação, de reconhecimento e de descobertas de si

4 Em 1942, foi incluido na obra póstuma A morte da mariposa. Em 2012, com reimpressão em agosto de 2017, passou a integrar a obra Profissões para mulheres e outros artigos feministas, organizada e publicada pela L\&PM Editores, com a tradução de Denise Bottmann, composta por mais seis ensaios. 
mesmas, corroborando com as distintas formas de atuação que alcança essa multiplicidade de vozes femininas na literatura. Essas vozes que estavam, de acordo com Gutiérrez, "ausentes de um cânon quase exclusivamente masculino e predominantemente do primeiro mundo, europeu e da classe dirigente" (GUTIÉRREZ, 2004, p.33) agora estão presentes e não há volta, mesmo que ameaçadoras, como explica Colasanti (1997, p. 41): a escrita produzida por mulheres pode ter caráter ameaçador, pois a linguagem utilizada é individual, rompendo com as normas e problematizando o estabelecido, ou seja, a mulher escritora torna-se uma questionadora ao produzir literatura, pois, como "criadoras, elas escapam ao controle, se transformam em ameaça" (COLASANTI, 1997, p.40).

Foi com esse objetivo, isto é, recuperar o espaço negado e a invisibilidade do passado e garantir, no presente, a visibilidade do protagonismo e das vozes em ação, que o presente dossiê, "História e literatura de mulheres nos séculos XIX e XX na América Latina", foi proposto. Levando em conta, portanto, o conjunto de artigos, esta edição organiza-se a partir de duas vertentes de trabalhos: por um lado, há pesquisas sobre a ampla interface que ocorre entre escrita e gênero. Sob este ângulo, alguns trabalhos priorizam debates teóricos e apresentações críticas sobre a historiografia, cânone e democratização da divulgação da autoria feminina pela América Latina (ou a falta dela). Por outro lado, há estudos que priorizaram uma autora ou uma obra ou ainda personagens que discutem, tematizam e refletem acerca de conceitos, ideias e representações de feminino, autoria feminina e mulher. No entanto, é indispensável alertar: estas duas percepções são encontradas tanto em um caso quanto em outro: os textos, em última instância, realizam os dois movimentos, concomitantemente. O que ocorre é a diferença no grau de intensidade entre uma forma de olhar e outra. Conforme será possivel identificar, alguns temas se mostram recorrentes nas leituras propostas - e como poderia ser diferente? Nação, pátria, identidade, voz, silenciamento, luta, força, presença, feminino, mulher, história, memória, cultura: esses são alguns dos sintagmas que compõem o pilar dos textos apresentados. $\mathrm{Na}$ narrativa ou na lírica, são alicerces a serem derrubados ou a serem fortalecidos.

Desta forma, buscando seguir a disposição sugerida, iniciemos uma breve trajetória por entre os trabalhos desse segundo enfoque, como se o mergulho proposto pelas autoras e pelos autores utilizassem de uma lente de aumento que busca, nas minúcias, um tesouro que é, ao mesmo tempo, um problema a ser pensado; em seguida, passaremos a olhar aquelas e aqueles que optam também por telescópios, lunetas e binóculos, que provocam nossa percepção para planos maiores, por vezes mais distantes, mas que, assim como as outras e os outros, encontram marcas, fazem apontamentos e desafiam novas possibilidades de ler e pensar a literatura.

Uma das autoras que vira tema nesta edição é Eliane Brum. Sua obra Meus desacontecimentos é analisada sob duas óticas: Karine Conte de Mattos da Costa, no trabalho intitulado "Uma escutadeira que conta: a memória como construtora de identidade e potencializadora da escrita em Meus Desacontecimentos, de Eliane Brum", propõe uma leitura na qual a narrativa de Brum funciona como um palco onde a personagem encena possibilidades de ser. Neste sentido, a partir de conceitos de Paul Ricoeur, AleidaAssmann e outros pensadores, o foco temático localizase na identidade da personagem feminina que se transforma, ascende e conquista espaço, corpo e voz; já no texto "O(s) lugar(es) de Meus desacontecimentos, de Eliane Brum, na diversificada paleta da autoficção", de Jeferson de Moraes Jacques, a pesquisa questiona e instiga reflexões acerca do projeto de escrita da obra: em que gênero, dentro do espectro de escritas do eu, encontra-se a obra de Eliane Brum? Ao realizar um levantamento sobre o termo autoficção, iniciado com o texto de Serge Doubrovsky, o autor instaura um debate teórico sobre fronteira e hibridismo da e na escrita de si.

De forma semelhante, Isabel Allende também recebe duas focalizações que partem em viagens distintas: Amanda da Silva Oliveira, em "A escrita 
feminina em La casa de losespiritus, de Isabel Allende", analisa os processos da historicidade relacionados à personagem Alba que, ao escrever a história de sua familia, reescreve um universo no qual sua(s) identidade(s) é/ são posta(s) em questão. Sob a perspectiva de ChimamandaAdichie no tocante à identidade e de Paul Ricoeur a respeito da memória, a autora realiza uma intersecção entre a escrita e a vida, indicando a necessidade do registro memorialístico como forma de existência e de resistência; por sua vez, Cecil Jeanine Albert Zinani realiza um estudo em paralelo que pondera a respeito da identidade da escrita das autoras, mas também de sua nação, no trabalho intitulado "Isabel Allende e Marcela Serrano: vozes chilenas na literatura latino-americana". Ao utilizar um conto de Allende e um romance de Serrano, a autora efetua uma investigação na linguagem, tanto em sua forma como em seu conteúdo, apoiada em pensadores como Jonathan Culler e Simone Beauvoir, que busca (re)pensar como o sujeito tido como feminino vive, existe historicamente e é capaz de se libertar da força simbólica e social que o reprime.

Outra escritora que teve suas obras revisitadas mais de uma vez nesta edição é Lygia Fagundes Telles: João Pedro Rodrigues Santos, em "A Ditadura Militar Brasileira e os romances As meninas e As horas nuas, de Lygia Fagundes Telles", opta por realizar um exame reflexivo a respeito de um momento histórico nacional que é ficcionalizado nos dois romances mencionados de Telles. Em seu trabalho, o autor parte de estudos de ElioGaspari e apresenta argumentos para a relação intima entre literatura e história, mostrando como ambas as formas de discurso se apropriam da linguagem de maneiras distintas para criar textos sobre um determinado assunto, um paralelo que é sempre palco para debates importantes sobre hibridismo discursivo; sob outra ótica, Marilia Garcia Boldorini e Roberta Barros Meira apresentam o texto "As filhas dos homens e os espelhos: o olhar feminino em romances de Raquel de Queiroz e Lygia Fagundes Telles", no qual através de um paralelo entre os livros As três Marias, de Queiroz, e As meninas, de Telles, as autoras identificam traços de denúncia social pela literatura: uma denúncia ao silenciamento e à exclusão das mulheres no século XX no Brasil. Ao revisar a história e a literatura sob a ótica de pensadoras como Mary Del Priore e Michelle Perrot, as autoras discutem questões da liberdade (em suas múltiplas manifestações) das mulheres pelo prisma das personagens dos romances.

Renata Fonseca Wolff apresenta a tese da protagonista oculta no conto "O inferno tão temido", de Juan Carlos Onetti. Ao elaborar um estudo sobre as estruturas do conto literário, a autora examina os reflexos e as consequências da estrutura linguística estabelecida como forma de não aproximar leitor e leitora e personagem. Em seu trabalho "Gracia César fora de foco: a protagonista oculta em «O inferno tão temido» de Juan Carlos Onetti", com o auxilio de Alonso Caballero e Julio Cortázar, o texto do escritor uruguaio é examinado em suas minúcias, possibilitando ao leitor e à leitora a realização de um itinerário pelas nuances discursivas que dizem respeito à personagem feminina em questão, Gracia César, que pouca é desvelada pela voz que a conduz. NatháliaHecz Couto, por sua vez, examina a narrativa epistolar em seu texto intitulado "Memória por correspondência: as cartas da artista colombiana Emma Reyes na rememoração da infância". Couto respalda-se no trabalho jornalístico de Diego Garzón, mas propõe uma leitura original a respeito da infância (re) construida nas correspondências da colombiana Emma Reyes, estabelecendo um vínculo fundamental entre memória e identidade. Ao olhar para as imagens recorrentes da reconstituição da infância apresentada por Reyes, a autora examina uma forma de manifestação do sujeito, que é impreciso e subjetivo, e coloca a obra na esteira dos estudos das chamadas escritas do eu.

Em "As biografias de Manuela Sáenz: Um embate de memórias, vozes e discursos", Rosane Cardoso destaca não apenas a importância política da figura emblemática de Manuela Sáenz, mas também seu legado no imaginário cultural, resgatando as biografias que apresentam diversas 
facetas e interpretações da mulher que se tornou personagem. Questiona-se, assim, a percepção acerca da mulher presente na política: como ela é percebida? Que memórias são registradas sobre este aspecto? E a vida pessoal, em que medida influencia na percepção do outro a respeito dela? Distante espacialmente, mas não no enfrentamento a um sistema historicamente opressor, o trabalho de Jaqueline Ferreira Borges apresenta outra mulher que enfrentou forças politicas e culturais para alcançar seus objetivos: no texto "A literatura de autoria feminina no Brasil: um estudo sobre a trajetória de Francisca Júlia", a autora mostra a importância da poeta Francisca Júlia para o campo literário brasileiro, firmandose como uma das primeiras mulheres a figurar no escalão dominador por homens. No entanto, seu nome raramente aparece nas histórias da literatura. É esta uma ótima oportunidade para pensar novamente sobre a instituição e perpetuação de um perfil no cânone literário.

Em "La escritura de ClorindaMatto y Laura RiescoUnsiglo de literatura femenina", Sara Beatriz Guardia apresenta duas autoras e duas obras que se distanciam em um século no tempo, mas que levantam questões semelhantes: a presença da mulher na literatura. São elas: Aves sinnido de ClorindaMatto de Turner, publicada em 1889, Ximena de dos caminos, de Laura Riesco, em 1994. A autora mostra como a escrita é uma forma de marcar a presença e a luta por liberdade e identidade, visto que as mulheres foram - e, infelizmente, ainda são - tratadas como objetos sobre os quais se produzem discursos. Os casos analisados mostram que as únicas capazes de falarem pelas mulheres são elas próprias, e que ninguém precisa dar-lhes voz, pois elas já a possuem. Sob a esteira de uma problemática semelhante, surge o trabalho "Literatura colombiana afrodescendente: voz afrofeminina no poema "Negra soy" de Mary Grueso Romero". Benedito Ubiratan Sousa Pinheiro Júnior, Adrielle Sena Branco e Íris Andrade Torres apontam para o papel fundamental da escrita das mulheres afrocolombianas como forma de registro histórico e identitário. Embasadas e embasado em Francineide Santos Palmeira, Alfredo Ocampo Zamorano, Guiomar CuestaEscobra e outras e outros, a leitura realizada acerca da obra de Mary Grueso Romero permite ao leitor e à leitora uma aventura sobre um plano enriquecido pelo local de fala dos estudos culturais, no qual uma mulher escreve sobre a perspectiva de uma personagem que se identifica também como mulher. Essa ação, que parece simples para muitos, possui uma grande força representativa. Concernente a isso, há o aspecto étnico-racial que permite a verdadeira apresentação da chamada voz afrocolombiana feminina por si e sobre si.

Brenda Carlos de Andrade, no texto "Lucía Miranda, Eduarda Mansilla e Rosa Guerra: três mulheres, uma personagem e dois desejos/ projetos", apresenta a distinção na escrita de mulheres a respeito da ficcionalização da história. O processo ficcionalizado, que diz respeito a movimentos fundacionais, está embasado na constituição das vozes de mulheres nas narrativas. Assim, o trabalho permite observar as diferentes técnicas e perspectivas adotadas nas duas obras em análise, o que leva a refletir também sobre as manifestações de um eu, que não é completo e permanente, mas mutável, múltiplo e plural. Pode-se estabelecer um diálogo com o trabalho intitulado "A personagem feminina em Margarida La Rocque: a ilha dos demônios, de Dinah Silveira de Queiroz", de Ana Cristina Steffen. Ainda que o enfoque dado à leitura da obra de Dinah Silveira de Queiroz não seja especificamente o da história em sintonia com a literatura, este é um dos pontos que emerge da análise realizada. Mas, sobretudo, o que parece estabelecer uma conexão mais apurada é o tratamento dado à personagem feminina na narrativa, que é revestida de uma ânsia por descobrir e protagonizar a própria história de vida. Em ambos os trabalhos, as personagens não são acessórias da história, mas agentes conscientes de seus destinos. Ao partir de estudos de Ruth Silviano Brandão, Rita Schmidt e outras pesquisadoras, Ana Cristina Steffen propõe uma leitura renovada acerca de uma autora que, sem dúvidas, também merece nova atenção da crítica especializada e de leitores e leitoras. 
Em "El imaginario de lanación desde el exilio enla obra y enlacorrespondencia de ClorindaMatto de Turner", Fanny Arango-Keethapresenta um estudo acerca de um projeto literário de ClorindaMatto de Turner, que parte em exilio do Peru, mas que segue imaginando e construindo utopias da nação que precisou deixar para trás. Esse imaginário de nação surge através de escritas autobiográficas, que registram suas posições politico-sociais e também sua condição identitária. Como forma de discutir questões caras à contemporaneidade, tais como exílio, pátria, nação, identidade e ideologia, além do gênero literário que diz respeito à escrita de si, memória e autobiografia, a autora apoia-se em estudos de Isabel Allende, Leonor Arfuch e Mary Louise Pratt. Mariana Marise Fernandes Leite, no texto "De Josefina Bórquez a Jesusa Palancares: do individual ao coletivo em Hasta no verte JesúsMio" realliza uma leitura da obra de Elena Poniatowska buscando identificar um movimento que parte do singular para o coletivo. A autora identifica um processo de universalização a partir de um indivíduo, como uma espécie de generalização discursiva das experiências, que, segundo ela, pode ser comparado também à noção de literatura que, não raras vezes, é tomada. Para construir seu trabalho, a autora embasa sua pesquisa em Beatriz Sarlo, Ana Costa e Maria Rita Kehl, além de outras estudiosas das questões de gênero, teoria literária e experiência. Tratase de uma discussão que recai também sobre o desaparelhamento de um sistema que julga e valora obras literárias com critérios desiguais.

Hugo Jesús Correa Retamar traz à tona o estudo intitulado "AlfonsinaStorni, uma mulher de voz poderosa na poesia latino-americana". Seu estudo demonstra como as denúncias de um sistema patriarcal opressor já eram introduzidos nos versos de Storni, no início do século $X X$. Assim, esse trabalho apresenta duas fortes características: por um lado, a temática social presente na obra poética da autora, cara aos discursos contemporâneos; por outro, abre-se um caminho nem sempre explorado: o do gênero poético como vertente possivel de explanar e debater assuntos que, embora partam de um eu autocentrado, dizem respeito a um senso coletivo. Nesse sentido, ao partir de estudos de Márcia Hoppe Navarro e Helena Percas, o autor apresenta uma discussão acerca dos direitos das mulheres sem deixar de lado a análise poética dos versos da autora, que apresentam uma rítmica consonante ao conteúdo: forte e incisiva. Ana Lúcia Trevisan e Luana Barossi, no texto "O insólito como estratégia discursiva em "Oso Blanco", de Mayra Santos-Febres" apresentam uma análise do conto da porto-riquenha que versa sobre outro aspecto fundamental dos estudos de gênero: o corpo. As autoras apresentam o insólito como uma metáfora narrativa: o discurso do "aparentemente impossivel" assemelha-se a um corpo transformado ou transmutado: um corpo de mulher que se altera, adapta-se. Ao partir de perspectivas de Todorov e Bakhtin, as autoras mostram como o corpo literário assume dimensões históricas, políticas e sociais. Trata-se de um debate cultural com raizes epistemológicas. O corpo-texto funciona como uma espécie de mecanismo para as possibilidades de se compreender o corpo-humano. E vice-versa.

Regia Agostinho da Silva e Rafaella Andréa Fernandez, no trabalho "Maria Firmina Dos Reis: Intérprete do Brasil" realizam ao menos dois movimentos: por um lado, fazem uma revisão da historiografia literária, recuperando as diversas facetas de Ursula; por outro, apresentam a autora como uma intérprete das questões femininas e étnico-racial do Brasil. Assim, o discurso literário bebe da fonte histórica novamente para tratar de assuntos por muitos maquiados e permeados por sombras, como a escravidão, o racismo e a misoginia. Tais aspectos servem para o embasamento discursivo da obra literária que mostrará uma visão sobre a constituição da nação. De forma semelhante, eis o trabalho de Gabriela Sánchez Medina e Ariadna Alvarado López intitulado "El uso político de literatura en México: lapatriaenpalabras de Esther Tapia de Castellanos". As autoras apresentam um projeto literária incursionado pela poeta mexicana que visa estabelecer um panorama cultural do México enquanto nação. A poesia de Esther Tapia 
apresentada no trabalho mostra a aceitação e a rebeldia, a reclusa e o ato de coragem, a inércia e a violência: todas as ações precisas para uma revolução dos costumes. Ao pensar o sujeito poético, ou melhor, a eu-lírica, as autoras apontam para a construção e estabelecimento de ideias de Pátria e, sobretudo, o papel da mulher nesses cenários.

Em "A trajetória de Rosa Maria Egipciaca e o silenciamento cultural dos africanos no romance de Heloisa Maranhão", Francine Vargas dos Santos Damasceno embasa seu estudo em pelo menos três condições: a da mulher, a étnico-racial e a histórico-cultural. O trabalho realiza uma revisão da literatura-história que articula narrativa ficcional e histórica de modo a criar personagenssimbolo de movimentos de desarticulação de ideias opressoras. Renato Kerly Marques Silva, em "As rotas do desejo de Zulé: faces da sexualidade em Del rojo de su sombra, de Mayra Montero" parte para a perspectiva do imigrante: os deslocamentos, as identidades, a expatriação e a repatriação são temas que surgem das reflexões propostas pelo autor. As tensões sociais no Haiti são expostas como manifestações de um centro que se encontra em condições complexas de vivência e sobrevivência, ao passo que o autor propõe uma revisão do conceito de família.

Para abrir o último ciclo de textos que encerra esta edição, há o texto de Andrea Cristiane Kahmann intitulado "Circulação da escrita de mulheres hispano-americanas no Brasil: uma crítica a partir da história da tradução". Nesse trabalho, a autora apresenta dados para construir sua crítica acerca da pouca quantidade de obras publicadas e editadas no Brasil cuja autoria diga respeito a mulheres hispano-americanas. O estudo faz uma crítica ao sistema chamado conservador, sob uma perspectiva decolonial. A análise de Kahmann é embasada na teoria da tradução e recepção de obras, a partir de estudos de Susan Bassnett, Peter Burke e outras e outros. A autora propõe uma relação entre a defasagem dessas traduções e publicações e a leitura às quais as mulheres têm acesso no país, de caráter essencialmente conservador, realizando uma crítica ao impacto que isso pode ter na história das mulheres e da leitura de modo geral. Outro trabalho que aborda a questão editorial é de autoria de Ana Elisa Ribeiro e Sérgio Karam: em "Editora Mulheres, ZahidéMuzart e um caso relevante de edição de livros feministas no Brasil", a autora e o autor fazem provocações sobre a história da edição de obras feministas - ou ainda a história feminista das edições - para se pensar quais as influências de um aspecto sobre o outro. Assim, o estudo faz uma análise do catálogo e da história da linha editorial encabeçada por ZahidéMuzart, propondo uma instigante leitura sobre os processos que antecedem a leitura, mas a fomentam: a seleção, edição e publicação das obras.

Aline Veingartner Fagundes, em "Disputas epistemológicas e ecologia dos saberes em dois romances de autoria de mulheres no Brasil" trata das obras Amrik (1997), da cearense Ana Miranda, e PonciáVicêncio (2003), da mineira Conceição Evaristo, com o objetivo de identificar e pensar a respeito dos conhecimentos estabelecidos nas obras. Ela parte de conceitos de Boaventura de Sousa Santos para provocar uma leitura que abarca a diversidade de manifestações de conhecimentos e ideias. Assim, ao estabelecer o diálogo entre as obras das autoras, a ecologia proposta por Fagundes diz respeito à capacidade da sustentabilidade das diferenças em um mesmo cenário, não se fazendo preciso sobrepor ideias e conceitos como 'mais verdadeiros' que outros. Por fim, o trabalho intitulado "Mulheres e literatura: vozes de reconhecimento, transgressão e identidade", de Daniela Rebeca Campos Atienzo e Maria Carolina de Godoy trata das poesisa de Cristiane Sobral e de Victoria Santa Cruz. As autoras realizam um estudo que pretende mostrar semelhanças no processo de identificação de mulheres negras, a partir dos versos das poetas citadas. Sob este âmbito, o processo de (re)conhecimento diz respeito tanto a um estatuto ontológico particular quanto um processo social coletivo.

Dessa forma, reconhecer-se na literatura diz respeito a compreender as diferentes camadas que podem compor um sujeito, compreendendo seu caráter ficcional, e traçando um paralelo com a realidade empírica: ser mulher não é um fenômeno único e exclusivo e facilmente explicável 
ou apreensivel. Contudo, só quem pode tentar dizer, mostrar e sentir tais possibilidades de ser são as próprias mulheres. Assim, os diversos trabalhos apresentados nesta edição parecem concordar em ao menos um ponto central: não há nada que possa impedir a legalidade, o direito e a urgência de se reconhecer, respeitar e entender a pluralidade plausivel de ser e manifestar-se como mulher.

\section{Referências}

CIXOUS, Hélène. The laugh of the Medusa. [1975]. In: WARHOL, Robyn R.; HERNDL, Diane P. Feminisms: an anthology of literacy theory and criticism. New Jersey: RutgersUniversity Press, 1997.

COLASANTI, Marina. Por que nos perguntam se existimos. In: SHARPE, Peggy (org.). Entre resistir e identificar-se: para uma teoria da prática da narrativa brasileira de autoria feminina. Florianópolis: Mulheres; Goiânia: Ed UFG, 1997. p.33-42. https://doi. org/10.2307/345789

GUTIÉRREZ ESTUPIÑÁN, Raquel. Una introducción a la teoría literario feminista. México: Instituto de Ciencias Sociales y Humanidades Benemérita Universidad Autónoma de Puebla, 2004. https://doi. org/10.20937/rica.2016.32.02.05

LOBO, Luísa. Literatura de autoria feminina na América Latina. Revista Mulher e Literatura, Rio de Janeiro, 1998. Disponivel em: http://www.openlink.com.br/ nielm/revista.htm. Acesso em: 30 dez. 2019.

NAVARRO, Márcia Hoppe (org.). Rompendo o silêncio: gênero e literatura na América Latina. Porto Alegre: Ed UFRGS, 1995

ZOLIN, L.O. Literatura de Autoria Feminina. In: BONNINI, T.; ZOLIN, L.O. (org.) Teoria Literária: Abordagens históricas e tendências contemporâneas. Maringá: Eduem, 2012. p. 327-336.

WOOLF, Virginia. Profissões para mulheres. In: WOOLF, Virginia. Profissões para mulheres e outros artigos feministas. Tradução Denise Bottmann. Porto Alegre: L\&PM, 2017. p. 09-19.

\section{Endereço para correspondência}

Regina Kohlrausch

Pontificia Universidade Católica do Rio Grande do Sul

Av. Ipiranga, 6.681, Prédio 8, sala 401.15

Partenon 97010-082

Porto Alegre, RS, Brasil

Sara Beatriz Guardia

Jr. Las Calandrias, 151, 291,

Santa Anita 15011

Lima, Peru.

Luis Alberto dos Santos Paz Filho

São Tomé, 244

São Tomé 94460-100

Viamão, RS, Brasil

\section{Regina Kohlrausch}

Pós-doutora em Estudios Literarios na Universidade de Vigo (UVIGO), Espanha, com bolsa CAPES/Fundación Carolina (2010-2011) Doutora e Mestre em Teoria da Literatura pela Pontifícia Universidade Católica do Rio Grande do Sul, professora titular, graduação e do Pós-graduação da área de Letras, da Escola de Humanidades da Pontifícia Universidade Católica do Rio Grande do Sul (PUCRS), onde atua como Decana Associada da Escola de Humanidades e Membro da Comissão Coordenadora do PPGL da PUCRS.

\section{Sara Beatriz Guardia}

Directora de la Cátedra UNESCO Patrimonio Cultural y Turismo Sostenible de Universidad de San Martín de Porres (USMP). Lima/Peru. Directora del Centro de Estudios La Mujer en la Historia de América Latina, CEMHAL. Directora de la Comisión del Bicentenario Mujer e Independencia en América Latina. Escritora. Autora de doce libros, y de nueve en la dirección de edición.

\section{Luís Alberto dos Santos Paz Filho}

Mestre em Teoria da Literatura pelo Programa de Pós-Graduação em Letras da Pontifícia Universidade Católica do Rio Grande do Sul (PUCRS), com bolsa CNPq. Graduado em Letras (português e literatura) pela Pontifícia Universidade Católica do Rio Grande do Sul, com bolsa PROUNI. Atualmente, doutorando em Teoria da Literatura pelo mesmo Programa, com bolsa Capes. Integra a Linha de pesquisa Literatura, Memória e História, onde se detém, sobretudo, a estudos da literatura brasileira, com enfoque maior ao gênerto da poesia lírica. 